\title{
PENINGKATAN PENGETAHUAN HUKUM LINGKUNGAN DAN ENGLISH CONVERSATION PENJAGA PANTAI MENDUKUNG PROGRAM WISATA BAHARI BATAM
}

\author{
Zuhdi Arman \\ Universitas Putera Batam (UPB), Batam, Indonesia \\ e-mail: zuhdi@puterabatam.ac.id \\ Tomi Arianto \\ Universitas Putera Batam (UPB), Batam, Indonesia \\ e-mail: tomi.arianto@puterabatam.ac.id
}

\begin{abstract}
The development of a tourist area must be supported by the facilities and quality of existing Human Resources knowledge in the local area; Namely knowledge of tourism activities, the ability and communication skills and understanding of the rules of the game with foreign tourists. Setokok Beach is one of the destinations taken into account in supporting the marine tourism area in Batam. For this reason, legal guidance is needed specifically relating to the environment and the legal rules governing environmental preservation to the community so that they can live a life of society, nation and state without doing any damage to the environment that is now rife in Batam for it as one of the areas around Batam island in order to be prevented about the dangers of environmental damage in accordance with the current of globalization and the development of the times so that inevitably the community is demanded to be able to know the ins and outs of legal issues related to preserving and protecting the environment especially to the people at Setokok beach. The method taught is in the form of fostering Understanding of Environmental Law and English conversation practice according to the needs and conditions of training participants. The results obtained through community service in Setokok Beach can be seen from the mastery of the ability to practice law and speaking conversation.
\end{abstract}

Keywords: Environment, Law, Conversation, Coast Guard, Setokok

\section{PENDAHULUAN}

Hukum lingkungan sebagai kesatuan ruang semua benda, daya, makhluk hidup, termasuk manusia dan perilakunya bagitu mempengaruhi alam itu sendiri (Zuhdi, 2019). Masyarakat akan pemahaman terhadap hukum lingkungan sangatlah kurang, karena terkadang sosialisasi terhadap peraturan tidak diketahui oleh masyarakat, khususnya masyarakat pesisir pantai. Minat dan pengetahuan masyarakat juga akan pemahaman hukum, khususnya hukum lingkungan sangat terbatas, sehingga pengelolaan di aspek hukum lingkungan selalu diabaikan.

Pantai Setokok termasuk dalam gugusan Kepulauan Riau, tepatnya terletak di pulau Rempang kelurahan Setokok kecamatan Bulang kota Batam. 
Lokasinya tidak begitu jauh dari pusat kota Batam, cukup melewati jembatan tiga Balerang, dan sekitar $2 \mathrm{~km}$ kemudiansudah bisa menemui pantai Setokok. Pantai Setokok merupakan salah satu pantai di Batam yang terkenal dengan keindahan pasir putihnya.Pantai ini memiliki hamparan pasir putih yang luas dengan tekstur pasir yang lembut. Hamparan pasir putih akan terlihat lebih mempesona apabila air laut sedang surut. Pada saat itu,bisa puas bermain maupun berfoto di hamparan pasir putih yang indah. Di tempat ini,bisa menyaksikan panorama alam bahari yang menyejukkan pandangan.Pasir putih bersih yang luas dan lautan biru yang membentang serta pulau-pulau kecil yang nampak kehijauan,membuat pantaiSetokok memiliki panorama yang sangat menenangkan.

Di sepanjang perjalanan,akan dimanjakan dengan pemandangan perbukitan yang hijau penuh akan berbagai jenis tanaman, baik itu tanaman liar maupun perkebunan. Jalan yang berkelok-kelok membuat sensasi perjalanan menjadi lebih menyenangkan dan bisa mendapatkan momen pada saat matahari tenggelam.Karena ombaknya yang tidak begitu besar pada waktu surut, menyebabkan pantai ini aman digunakan untuk bermain bahkan oleh anak-anak, namun harus tetap dengan pengawasan orangtua.

Dengan berbagai fasilitas yang telah tersedia,tidak perlu bingung lagi saat berlibur ke pantai Setokok ini. Kelestarian dan keindahan bentangan alam di pantai ini tentu saja sangat perlu dijaga, masyarakat harus mampu menganalisis mengenai dampak lingkungan sebelum lingkungan tercemar, makanya hal ini sangat perlu bagi mesyarakat sekitar diberi pembinaan terkait hukum lingkungan.

Banyak pelaku yang terlibat secara langsung terhadap wisatawan asing yang berkunjung ke pantai setokok ini seperti; penjaga pantai (guide), petugas pantai (cleaning service, securitydan lain-lain), pelaku Usaha mikro kecil menengah (UMKM), Jasa fotografer, pengelola pantai, serta masyarakat sekitar. Tentu saja bahasa inggris sebagai bahasa komunikasi internasional sangat dibutuhkan bagi para pelaku yang ada di pantai setokok tersebut. Hal ini juga merupakan pengabdian lanjutan dan pengembangan yang dilakukan oleh Arianto (2019) dalam rangka meningkatkan kemampuan berbahasa inggris agar mampu berkomunikasi dengan pengunjung mancanegara yang datang ke pantai indah setokok.

Dari hasil wawancara yang dilakukan penulis kelokasi, terdapat 12 orang penjaga pantai dan hampir 200 kepala keluarga yang tinggal disekitar pantai, sangat disayangkan sekali hampir tidak ada penjaga pantai, petugas, pelaku UMKM dan masyarakat disekitar pantai setokok yang mampu berkomunikasi dengan menggunakan bahasa inggris. Ketika wisatawan mancanegara datang berkunjung, masyarakat dan penjaga pantai hanya menggunakan bahasa isyarat atau tidak berkomunikasi sama sekali. Tentu saja hal ini berdampak pada semakin berkurangnya peluang ekonomis yang mereka dapatkan dan meninggalkan kesan yang tidak nyaman dan memuaskan bagi pengunjung asing yang datang kesana.

Berdasarkan permasalahan yang dihadapi oleh penjaga pantai, pelaku UMKM, dan masyarakat disekitar pantai setokok, maka tim pengabdi masyarakat terdiri dari 3 orang memberikan pelatihan pembinaan hukum lingkungan dan pelatihan bahasa inggris khususnya pada kemampuan berkomunikasi (Speaking English Skill). Hal ini dilakukan agar penjaga pantai dapat memberikan guiding yang baik, petugas pantai bisa memberikan instruksi dan petunjuk dengan lancar, pelaku UMKM dapat menawarkan produk belanjaannya, jasa fotografer dapat menawarkan jasanya, serta masyarakat sekitar juga dapat berkomunikasi 
dengan menggunakan bahasa inggris yang baik terhadap wisatawan mancanegara yang berkunjung di pulau Setokok.

\section{METODE}

\subsection{Waktu dan Tempat Pelaksanaan}

Kegiatan pengabdian kepada masyarakat ini dilakukan secara bertahap mulai tanggal 17 dan 24Februari 2019yang terbagi menjadi 2 pertemuan di tempat yang berbeda seperti yang dijelaskan pada tabel berikut ini :

Tabel 3.1 Waktu dan tempat pelaksanaan

\begin{tabular}{|c|c|c|c|}
\hline Hari & Kegiatan & Nama Pelaksana & $\begin{array}{c}\text { Alokasi } \\
\text { Waktu } \\
\text { jam/minggu }\end{array}$ \\
\hline \multirow[t]{3}{*}{ Hari I } & Pembukaan & Protokol & 10 Menit \\
\hline & $\begin{array}{l}\text { Memberikan pelatihan cara } \\
\text { menganalisa dampak } \\
\text { lingkungan berdasarkan } \\
\text { aturan-aturan }\end{array}$ & Dosen Hukum & 15 Menit \\
\hline & $\begin{array}{l}\text { Memberikan motivasi untuk } \\
\text { mampu berbahasa Inggris } \\
\text { dan Memberikan teori } \\
\text { tentang bahasa Inggris }\end{array}$ & Dosen Sastra Inggris & 15 Menit \\
\hline \multirow[t]{2}{*}{ Hari ke II } & $\begin{array}{l}\text { Memberikan pelatihan } \\
\text { lanjutan mengenai cara } \\
\text { menganalisis dampak } \\
\text { lingkungan agar tetap } \\
\text { terjaga. }\end{array}$ & $\begin{array}{l}\text { Dosen Hukum dan } \\
\text { Mahasiswa }\end{array}$ & 30 Menit \\
\hline & $\begin{array}{l}\text { Memberikan pelatian } \\
\text { lanjutan conversation dan } \\
\text { kosakata berkaitan dengan } \\
\text { pantai. }\end{array}$ & Dosen Sastra Inggris & 15 Menit \\
\hline
\end{tabular}

Untuk lebih jelasnya lokasi pengabdian yang dilaksanakan di Pantai Pulau Setokok dapat dilihat pada peta dan gambar di bawah ini : 

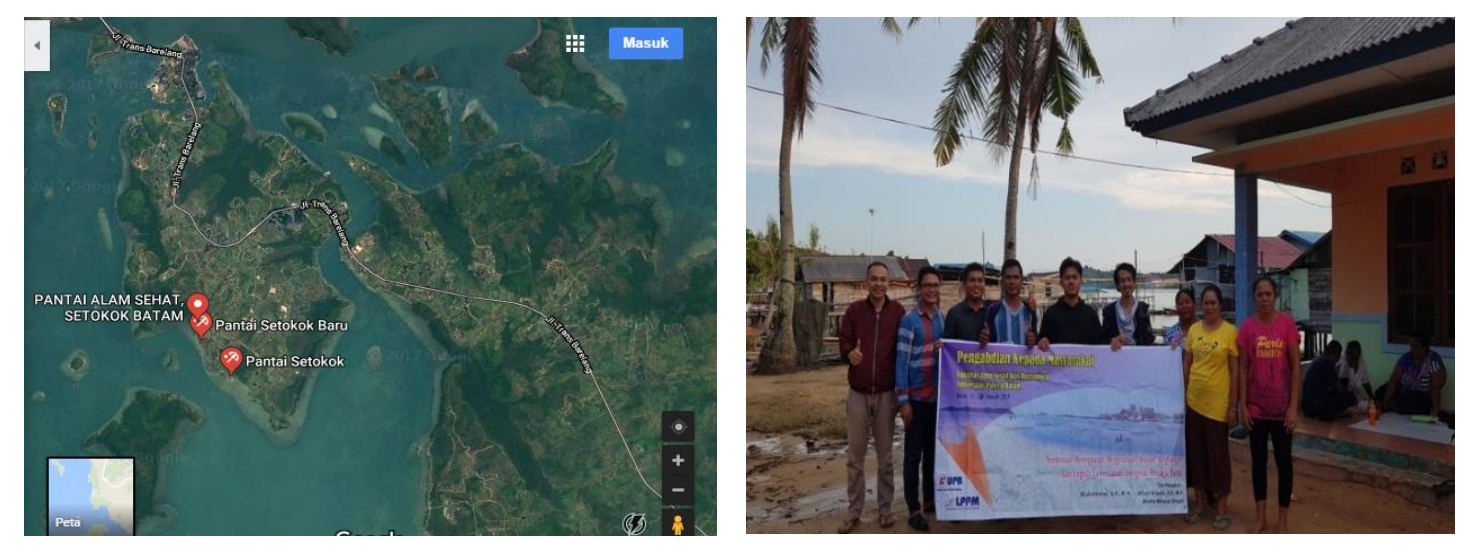

Gambar 2.1 Lokasi kegiatan

\subsection{Metode pelaksanaan}

Metode yang dilakukan untuk menyelesaikan permasalahan oleh tim pengabdi adalah :

1. Melaksanakan wawancara (in-depth interview) untuk mengetahui karakteristik penjaga pantai dan masyarakat yang terlibat di lingkungan pantai pulau setokok.

2. Memberikan pemahaman terkait Hukum lingkungan dan pelatihan menganalisis mengenai dampak lingkungan, terkait bagaimana tindakan preventif untuk menjaga kelestarian di lingkungan pantai pulau setokok.

3. Memberikan masukan terkait akibat yang terjadi jika lingkungan pantai tidak di lakukan tindakan preventif.

4. Memberikan pretest kepada calon pembelajar berbentuk tanya-jawab sederhana dalam bahasa Inggris untuk mengetahui kemampuan berbahasa Inggris

5. Melaksanakan pelatihan dengan memberikan contoh-contoh percakapan seperti greeting, giving direction, asking and answering questions, asking for clarification, offering, and persuading serta kosakata bahasa Inggris (vocabulary) dengan teknik sesuai kebutuhan masing-masing.

6. Memberikan contoh-contoh percakapan berbahasa Inggris antara penjaga pantai dan pengunjung melalu slides dan memberi kesempatan untuk berlatih dalam kelompok (in-pair group)

7. Melakukan praktik langsung di lokasi pantai antara penjaga pantai, pelaku UMKM, fotografer, masyarakat dan pengunjung pantai (posttest).

8. Memberi masukan kelebihan dan kekurangan berbahasa Inggris hasil dari posttest (refleksi)

\section{HASIL DAN PEMBAHASAN}

\subsection{Hasil Pengabdian}

Indonesia yang diamanatkan oleh Undang-Undang Dasar 1945 yang merupakan negara hukum, maka sangat diperlukan Pembinaan peningkatan pengetahuan hukum, khususnya hukum lingkungan yang terkait dengan English Conversation dalam rangka Pembinaan SasaranMasyarakat terhadap penjaga objek wisata pantai setokok (Zuhdi, 2018). Kegiatan pengabdian yang 
dilaksanakan selama dua hari tersebut diikuti dengan seksama dari awal hingga akhir pelatihan.Para peserta juga melibatkan anak muda untuk mengikuti kegiatan ini karena mereka banyak berinteraksi dengan wisatawan asing dan juga terlibat sehari-hari dalam kegiatan pantai.Kegiatan pembinaan peningkatan Pengetahuan Hukum Lingkungan dan kemampuan bahasa inggris ini dilaksanakan di sekitar pantai setokok dan balai pertemuan masyarakat.

Pada pertemuan hari pertama, tim pengabdi masyarakat memperkenalkan rencana pembinaan yang akan dilaksanakan selama dua hari. Sebelum memulai pembelajaran, tim melakukan diskusi singkat untuk mengetahui sejauh mana kemampuan dan pemahaman peserta dalam pengetahuan Hukum Lingkungan dan menggunakan bahasa inggris. Seperti informasi yang sebelumnya didapatkan, pengetahuan mengenai hukum lingkungan dan kemampuan bahasa inggris peserta pembinaan sangat kurang.Aspek Hukum yang mereka ketahui sangat minim dan Kosakata dalam bahasa inggris yang mereka miliki sangat terbatas. Beberapa orang penjaga pantai dan anak muda telah mendapatkan pembelajaran pengetahuan Hukum Lingkungan dan bahasa inggris. Dalam prakteknya mereka tidak memiliki pengetahuan dan memiliki kepecayaan diri untuk mempraktekan percakapan masih sangat kurang. Selanjutnya, tim pengabdian memberikan pembinaan pertama mengenai aspek Hukum Lingkungan, bagaimana dari tindakan preventif dan tindakan reprensif. Pemahaman mengenai aspek tersebut mesti diterapkan dalam penjagaan lingkungan, terutama lingkungan sekitar pantai setokok.

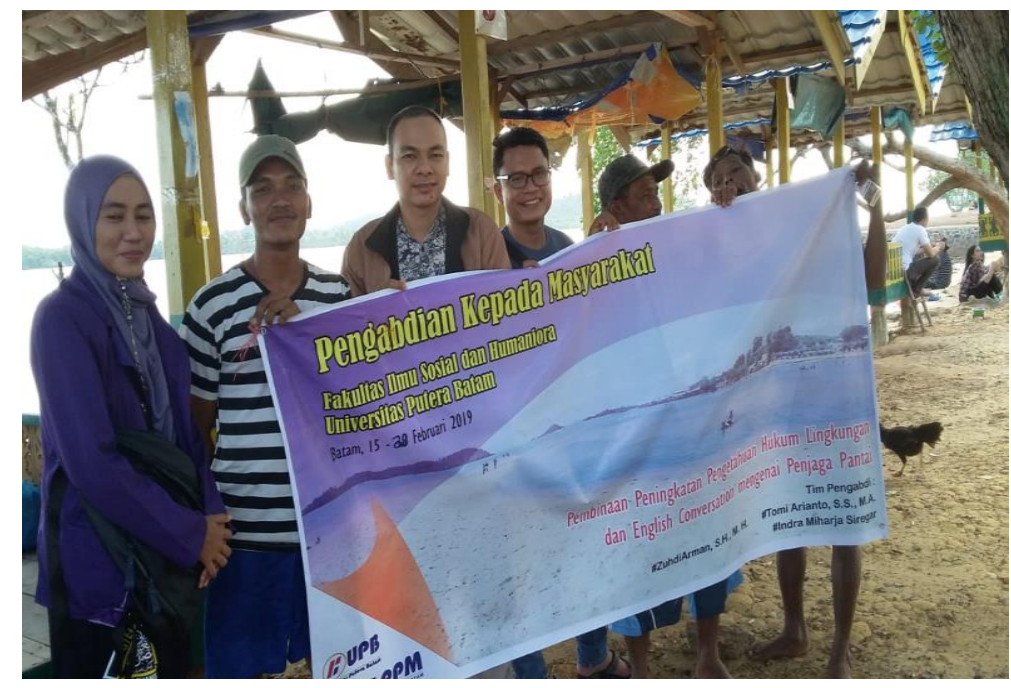

Gambar 3.1 Pertemuan Pertama Pembinaan

Pertemuan kedua, tim pengabdi melanjutkan pembinaan dengan memberikan teori dan dilanjutkan dengan simulasi praktek percakapan secara kelompok dan individu. Materi yang diajarkan dipertemuan ini berupa dengan memberikan contoh-contoh percakapan seperti greeting, giving direction, asking and answering questions, asking for clarification, offering, and persuading. Tim pengabdi juga memberikan kosakata yang berkaitan dengan pantai bagi peserta untuk selanjutnya bisa dihafal diluar pertemuan pengabdian.Peserta juga diminta untuk mempraktekan secara berkelompok dengan pasangannya secara tekstual dan non-tekstual. Tim pengabdi juga menggunakan alat bantu berupa kertas materi agar peserta lebih fokus dan terarah mengikuti pelatihan. 


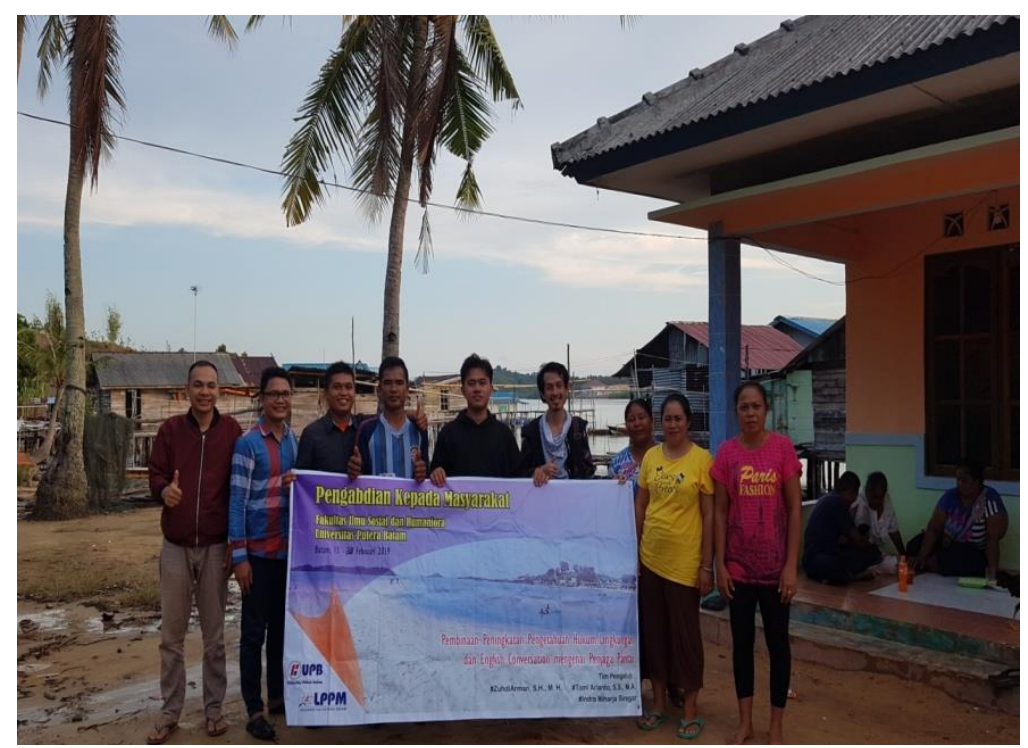

Gambar 3.2 Pertemuan Kedua Pembinaan

Hasil dari pelatihan ini dapat dilihat dari pemahaman terhadap hukum lingkungan dan simulasi percakapan salah satu perserta penjaga pantai dalam menggunakan bahasa inggris. Peserta mulai bisa memberikan kalimat sapaan, memberikan arah, dan informasi sikat pantai.Penguasaan percakapan bahasa inggris harus selalu dipraktekan agar apa yang telah diajarkan tetap melekat dan semakin biasa digunakan, dan praktek terhadap menjaga lingkungan menjadi lingkungan pantai yang asri merupakan wujud msyarakat penjaga pantai terhadap pemahaman hukum lingkungan, dan juga motivasi selalu disampaikan oleh tim pengabdi kepada masyarakat agar peserta tidak segan mempraktekan bahasa inggris kepada wistawan mancanegara yang datang ke pantai setokok.

\subsection{Pembahasan}

Objek wisata pantai setokok merupakan satu destinasi yang banyak dikunjungioleh wisatawan mancanegara.Penjaga pantai merupakan yang yang berinteraksi langsung dengan para pengunjung.Kemampuan berkomunikasi menggunakan bahasa inggris sangat diperlukan dalam menjaga stabilitas pengunjung ke objek pantai tersebut.Kegiatan pengabdian yang dilakukan dapat memberikan bagi penjaga pantai dan masyarakat sekitar untuk memahami bahaya dampak lingkungan dan bisa mencegah melalui analisis berdasarkan perspektif hukum lingkungan dan meningkatkan pendapatan melalui kemampuan berkomunikasi bahasa Inggris dengan baik.Pelaksanakan pelatihan berbahasa Inggris baik teori dan praktik yang disesuaikan dengan keadaan serta kebutuhan pelaku yang terlibat di objek wisata pantai pulau setokok. 


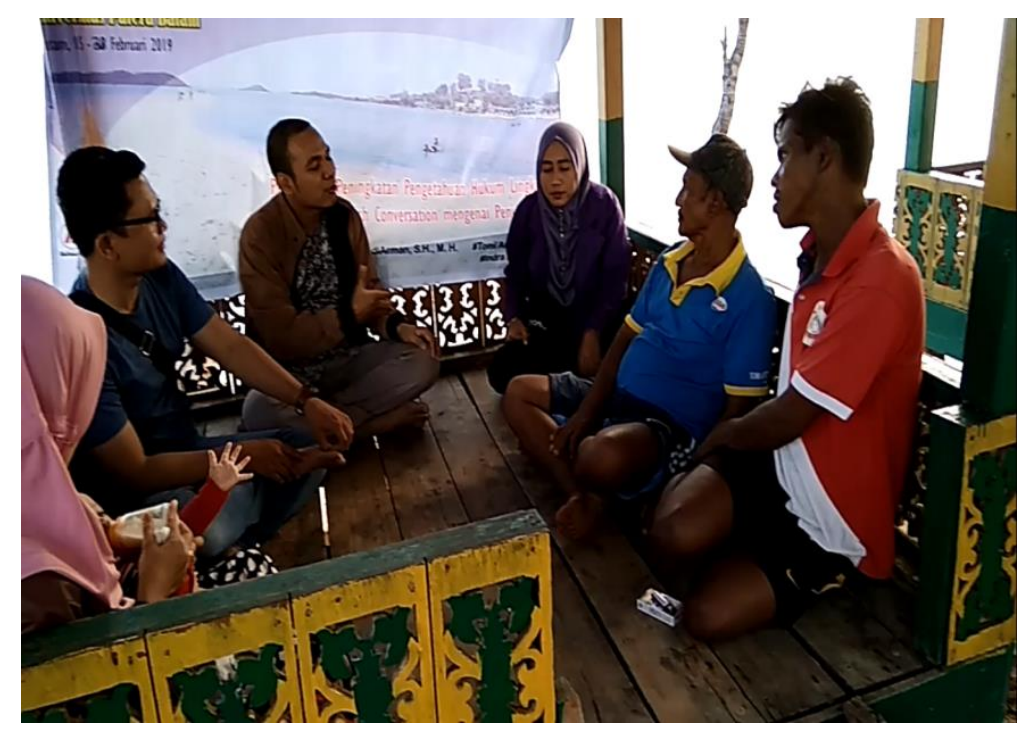

Gambar 3.3 Interaksi Mempraktekkan Pemahaman Hukum Lingkungan dan Berbahasa Inggris

Selain itu, Pengunjung bisa memanfaatkan penawaran jasa lainnya jika berani berkomunikasi bahasa inggris kepada pengunjung yang datang. Di pantai setokok sendiri ada banyak fasilitas jasa yang bisa dijajakan seperti fasilitas bermain air dengan kayaking, menaiki perahu sampan, berenang menggunakan benen, tempat bersantai di pondok dan hall, ruang pertemuan dan acara resepsi, makanan, hiburan, bahkan fasilitas toilet dan kamar mandi.

Kemampuan bahasa inggris yang kurang dimiliki oleh penjaga pantai menjadi keluhan sendiri bagi peserta.Pada hari pertama melakukan pelatihan, peserta hampir tidak memahami bagaimana memperkenalkan diri atau menyapa pengunjung wisatawan yang datang.Banyak dari peserta yang mengeluh karena tidak berani menyapa turis mancanegara.Para pelayan pantai rata-rata memiliki pendidikan rendah, sebagian ada yang kehilangan pekerjaan karena di PHK dari perusahaan. Kehadiran tim pengabdi memberikan harapan baru bagi penjaga pantai untuk dapat menambah pengetahuan tentang lingkungan dan kemampuannya berbahasa inggris. Sebagian mereka juga membawa anggota keluarganya atau anaknya untuk mengikuti pembinaan.Anak mereka juga sering dilibatkan dalam aktifitas pantai seperti melayani pengunjung di foodcout, atau menjajakan makanan.

\section{KESIMPULAN}

Hasil dari pengabdian ini memberikan manfaat yang banyak bagi warga selain meningkatkan pengetahuan masyarakat bidang hukum lingkungan dapat memahami aturan-aturan hukum yang sudah dikeluarkan pemerintah sebagai batasan-batasan masyarakat dalam pengelolaan lingkungan pantai.

Dalam hal meningkatkan pendapatan melalui kemampuan berkomunikasi bahasa Inggris dengan baik. Pelaksanakan pelatihan berbahasa Inggris baik teori dan praktik yang disesuaikan dengan keadaan serta kebutuhan pelaku yang terlibat di objek wisata pantai pulau setokok. 


\section{SARAN}

1. Perlu adanya keberlajutan dari pengabdian ini agar dapat memonitoring petugas sehingga program yang sudah dibuat dapat efektif dimanfaatkan dan tujuan untuk peningkatan taraf ekonomi warga dapat tercapai.

2. Peningkatan pengabdian, misalnya membantu petugas pantai untuk memudahkan dan meningkatkan kemampuan komunikasi dengan para wisatawan khususnya wisatawan asing.

\section{UCAPAN TERIMA KASIH}

Penulis mengucapkan terimakasih yang sebesar-besarnya kepada Universitas Putera Batam terutama Tim LPPM UPB atas bimbingan dan arahannya sehingga dapat menyelesaikan proses pengabdian ini. Selain itu juga, penulis mengucapkan terimakasih kepada mahasiswa dan masyarakat atau peserta pengabdian yang telah serius mengikuti pembinaan bahasa ini hingga akhir. Semoga ilmu yang didapatkan bisa bermanfaat dan diterapkan dalam pekerjaan.

\section{DAFTAR PUSTAKA}

Arianto, T. (2019). Pembinaan Peningkatan English Conversation di Pantai Indah Setokok. Jurnal Puan Indonesia, 1(1), 10-18.

http://idebahasa.or.id/puanindonesia/index.php/about/article/view/2

Ukas, Zuhdi A. (2019). Hukum Dan Pengelolaan Limbah Bahan Berbahaya dan Beracun (B3) Wilayah Perbatasan Negara Di Kepulauan Riau.Jurnal Hukum Samudra Keadilan.Vol 14, No 2. https://ejurnalunsam.id/index.php/jhsk/article/view/1609

Yona, May. (2016). Kumpulan Materi Pembelajaran Bahasa Inggris untuk Pemula. Retrieved from http://kuliahbahasainggris.com/2017/12/12/materpembelajaran-untuk-bahasa-inggris-pemula

Zuhdi Arman. (2018). Tinjauan Terhadap Sistem Multi Partai Dalam Sistem Pemerintahan Presidensial Di Indonesia Pada Era Reformasi,Jurnal Cahaya Keadilan, Vol 6, No.1. http://ejournal.upbatam.ac.id/index.php/cahayakeadilan/article/view/875

Zuhdi Arman. (2019). Analisis Terhadap Pengujian Undang-Undang Nomor 42 Tahun 2008 Tentang Pemilihan Umum Presiden Dan Wakil Presiden, Jurnal Cahaya Keadilan, Vol $\quad 7, \quad$ No.1. http://ejournal.upbatam.ac.id/index.php/cahayakeadilan/article/view/1199 